\title{
Effects of Manufacturing Process Conditions on Sensory Attributes and Microstructure of Ice Cream
}

\author{
Keisuke Inoue*, Yosuke Ishii, Makiko Iwata, Masayoshi Taketsuka, \\ Nobuo Ichihashi, Keiji Iwatsuki and Kiyoshi Toko ${ }^{1}$ \\ Food Research \& Development Institute, Morinaga Milk Industry Co., Ltd., \\ 5-1-83, Higashihara, Zama, Kanagawa 252-8583, Japan \\ 'Department of Electronics, Graduate School of Information Science and Electrical Engineering, \\ Kyushu University, 744, Motooka, Fukuoka 819-0395, Japan
}

(Received April 15, 2011; accepted July 4, 2011)

Key words: ice cream, sensory evaluation, continuous freezer, homogenizer, odor sensor

The primary process parameters of the homogenization pressure and freezing process (drawing temperature and overrun) for ice cream manufacture were examined to determine their impact on the sensory attributes and odor sensor response of ice cream. Fifteen process conditions were selected using a Box-Behnken design, while 12 sensory attributes were obtained as assessment items based on sensory evaluations using quantitative descriptive analysis (QDA). Eleven of these sensory attributes changed significantly according to process conditions, suggesting that such conditions can have a major impact on ice cream's sensory attributes, even for a fixed make-up of ingredients. Furthermore, observed correlations between the sensory attributes and microstructural attributes of the ice cream led to the conjecture that the sensory attributes were influenced by changes to the ice cream's structural conditions resulting from the process conditions. A correlation was also observed between the odor sensor response and the overrun condition, but no clear correlations were found to exist within the ice cream structure or the sensory attributes.

\section{Introduction}

The palatability of ice cream is mainly determined by two factors: ingredients and process conditions. Numerous studies have addressed the relationship between ingredients and palatability, with differences reported in terms of aroma, mouthfeel, and taste according to fat content, ${ }^{(1)}$ protein, ${ }^{(2,3)}$ and interaction between sugar and fat. (4) Other studies have shown that ice creams using vegetable fats slightly surpass those containing milk fats in terms of flavor release ${ }^{(5)}$ and that the perception of vanilla ${ }^{*}$ Corresponding author: e-mail: ke-inoue@morinagamilk.co.jp 
aroma declines as milk fat content increases. ${ }^{(6)}$ Schirle-Keller et al. ${ }^{(7)}$ attribute this to a reduction in headspace aroma components caused by the trapping of lipophilic volatiles in the food's lipid components.

Meanwhile, in terms of the relation to process conditions, Akalin et al. ${ }^{(8)}$ reported that a longer aging time (such as 24 instead of $4 \mathrm{~h}$ ) produces an increased favorable texture and appearance, and Kokubo et al. ${ }^{(9)}$ stated that freezing conditions have an effect on ice cream's dryness. Furthermore, Windhab and Wildmoser ${ }^{(10)}$ reported that the refrigeration equipment known as a low-temperature extruder (LTE), which provides additional refrigeration at low temperatures $\left(-12\right.$ to $\left.-18^{\circ} \mathrm{C}\right)$ after freezing, improves ice cream's creaminess, coldness, and hardness. However, despite all the evidence that process conditions clearly alter the sensory attributes of ice cream, there have been few studies on the subject.

In a previous study focusing on freezing, which is the principal process in the manufacture of ice cream, we demonstrated that the condition settings can cause a significant variation in the fat destabilization rate, air bubble diameter, and ice crystal diameter in the microstructure. ${ }^{(11)}$ We also identified a correlation between these air bubbles, ice crystals, and fat destabilization, as well as the hardness and melt-inmouth qualities of the ice cream. ${ }^{(12,13)}$ The finding that a food matrix structure plays an important role in controlling flavor release ${ }^{(14)}$ suggests that variations in the structure of ice cream, owing to process conditions, also affect changes in sensory attributes such as aroma and flavor.

Hence, in the present study, we investigated the effects of three factors on the sensory evaluation of ice cream. These are the two freezer parameters of drawing temperature $\left({ }^{\circ} \mathrm{C}\right)$ and overrun (\%), which have the greatest impact on the structure and physical properties of ice cream, and the pressure used in the homogenization process, which determines the fat globule diameter. We then studied the relationship between the sensory attributes and the structure of ice cream.

We also used an odor sensor capable of quantitative and inexpensive analysis of volatile compounds and aromas relative to sensory evaluation. This device utilizes technology that classifies and distinguishes between multicomponent aromas based on statistical analysis of sensor resistance. ${ }^{(15)}$ Recent studies have employed this sensor as a new analytical technique during food evaluation to assess the difference in sensory attributes resulting from differences in the process conditions of coffee and milk beverages. $^{(16-18)}$ In this study, we examined whether the odor sensor could also be used to evaluate the flavor of semisolid foods such as ice cream.

\section{Materials and Methods}

\subsection{Setting of ice cream process conditions and sampling}

The ingredients, mixed in accordance with Table 1, were first dispersed and dissolved in $70^{\circ} \mathrm{C}$ water using a super mixer (Yasuda Corporation, Japan). Next, the formulation was applied to a plate pasteurizer (MD Plate Exchanger FBS-3 SS; Morinaga Engineering Co., Ltd., Japan) and subjected to high-temperature-short-time (HTST) pasteurization for $30 \mathrm{~s}$ at $95^{\circ} \mathrm{C}$, after which the resultant fat globules were homogenized 
Table 1

Ice cream mix formulation.

\begin{tabular}{lr}
\hline Ingredient & Ratio \\
\hline Skim milk powder & 10.12 \\
Unsalted butter & 11.31 \\
Sugar & 7.50 \\
High-fructose corn syrup (TS67.5\%) & 7.00 \\
Corn syrup powder (DE27) & 6.00 \\
Emulsifier* & 0.25 \\
Stabilizer** & 0.25 \\
Vanilla extract & 0.10 \\
Water & 57.47 \\
\hline
\end{tabular}

*Glyceryl mono-distearate

${ }^{* *} 45.0 \%$ locust bean gum, $45.0 \%$ guar gum, and $10.0 \%$ carrageenan

in a two-stage homogenizer (Sanmaru Machinery Co., Ltd., Japan). The mix was then cooled to $5^{\circ} \mathrm{C}$ and kept at this temperature for aging for over a full day. The composition of the resulting ice cream mix contained $9.5 \%$ milk fat and $37.8 \%$ total solids. The ice cream mix was then subjected to freezing. A Box-Behnken design was prepared for the homogenization process condition of total homogenization pressure (Pre) and the freezing process conditions of the drawing temperature (Tem) and overrun (Ovr) on the basis of the ranges in Table 2, and 15 sampling conditions including two repetitions at the center were obtained (Table 3 ). The homogenization pressure used in the experimental design was the total pressure, while the second-stage pressure levels used to inhibit the formation of posthomogenization fat globule clusters were all set at 2.0 MPa. Overrun is the ratio of air in the ice cream and is calculated with the following equation:

$$
\operatorname{Ovr}(\%)=\frac{V_{\text {ice }}-V_{\text {mix }}}{V_{\text {mix }}} \times 100,
$$

$V_{\text {ice }}$ : ice cream volume; $V_{\text {mix }}:$ ice cream mix volume.

On the basis of this experimental design, the process conditions were set, and the prepared ice cream was used to fill $130 \mathrm{ml}$ conical paper sampling cups. The other freezing parameters were: mix flow rate $(75 \mathrm{~L} / \mathrm{h})$; dasher speed $(222 \mathrm{rpm})$; and cylinder pressure $(300 \mathrm{kPa})$. A standard type 30 dasher was used. After filling the sampling cups, the ice cream was hardened and kept in a cold storage room at $-35^{\circ} \mathrm{C}$.

\subsection{Sensory evaluation}

Sensory evaluation was performed using qualitative descriptive analysis (QDA). Eleven panelists (all women) with sensory evaluation experience ranging from six months to four years and 10 months were selected and underwent nine additional training sessions (totaling $30 \mathrm{~h}$ ) for the purpose of this experiment.

In selecting the sample sensory attributes required for evaluation (evaluation terms 
Table 2

Settings for process conditions.

\begin{tabular}{llcrcc}
\hline & & \multicolumn{3}{c}{ Level } \\
\cline { 3 - 5 } Process & Parameter & Abbreviation & -1 & 0 & +1 \\
\hline Homogenization & Pressure $(\mathrm{MPa})$ & Pre & 6.0 & 15.0 & 24.0 \\
Freezing & Drawing temperature $\left({ }^{\circ} \mathrm{C}\right)$ & Tem & -6.5 & -5.0 & -3.5 \\
& Overrun $(\%)$ & Ovr & 30 & 65 & 100 \\
\hline
\end{tabular}

Table 3

Sampling condition according to Box-Behnken design.

\begin{tabular}{crrr}
\hline \multirow{2}{*}{ Sample } & \multicolumn{3}{c}{ Process } \\
\cline { 2 - 4 } & Pre & Tem & Ovr \\
\hline 1 & 15 & -5.0 & 65 \\
2 & 15 & -5.0 & 65 \\
3 & 6 & -3.5 & 65 \\
4 & 15 & -6.5 & 100 \\
5 & 15 & -3.5 & 100 \\
6 & 24 & -3.5 & 65 \\
7 & 24 & -6.5 & 65 \\
8 & 6 & -5.0 & 100 \\
9 & 6 & -5.0 & 30 \\
10 & 15 & -3.5 & 30 \\
11 & 6 & -6.5 & 65 \\
12 & 15 & -6.5 & 30 \\
13 & 15 & -5.0 & 65 \\
14 & 24 & -5.0 & 100 \\
15 & 24 & -5.0 & 30 \\
\hline
\end{tabular}

and physical reference standards), three representative samples that were characteristic in terms of sensory attributes were assigned three-digit random numbers and provided to the panelists who then evaluated them independently, thus determining and defining the general sensory attributes, tastes, flavors, and textures required for evaluation. The panelists then discussed and reorganized the sensory attributes and respective definitions to reach a consensus (wherever possible), and ultimately established and defined a list of 12 attributes (Table 4).

During the evaluation process, a portion of each sample was assigned a random three-digit number and then provided to each of the 11 panelists who performed their evaluation in separate booths. The intensity of each sensory attribute was measured using a $100 \mathrm{~mm}$ linear scale marked ' 0 ' at one end and ' 100 ' at the other, wherein 0 represents no intensity and 100 indicates a very high level of intensity. The panelists evaluated their assigned portion of the sample by drawing a vertical line on the scale corresponding to their assessment of the intensity of each attribute. The distance from the end of the scale $(\mathrm{mm})$ was recorded as the evaluation score. Each sample was 
Table 4

Sensory attributes tested by the panel.

\begin{tabular}{|c|c|c|c|}
\hline Attribute & & Abbreviation & Definition \\
\hline \multicolumn{4}{|l|}{ Aroma } \\
\hline & Overall vanilla intensity & $V I$ & $\begin{array}{l}\text { Overall vanilla aroma associated with vanilla, as in } \\
\text { vanilla extracts or ethyl vanillin }\end{array}$ \\
\hline & Creamy vanillin & CV & $\begin{array}{l}\text { Sweet aroma associated with vanilla, as in vanilla } \\
\text { extracts or ethyl vanillin }\end{array}$ \\
\hline & Phenolic & $\mathrm{PH}$ & $\begin{array}{l}\text { Aroma associated with smoky notes found in vanilla } \\
\text { extracts or vanilla beans }\end{array}$ \\
\hline & Caramel & $C A$ & $\begin{array}{l}\text { Sweet brown aroma associated with sugar that has } \\
\text { been subjected to heat, as found in chewy sweets }\end{array}$ \\
\hline & Overall milk intensity & MI & $\begin{array}{l}\text { Overall milk aroma associated with fresh milk or } \\
\text { milk-derived products }\end{array}$ \\
\hline & Fresh milk & $F M$ & Aroma associated with fresh milk \\
\hline & Skim milk powder & $S M$ & Aroma associated with skim milk powder \\
\hline & Fatty dairy & $F D$ & $\begin{array}{l}\text { Creamy, milky, buttery aroma associated with dairy } \\
\text { products }\end{array}$ \\
\hline & Creamy & $C R$ & $\begin{array}{l}\text { Aroma associated with full fat cream, whipped cream, } \\
\text { or buttermilk }\end{array}$ \\
\hline \multicolumn{4}{|l|}{ Texture } \\
\hline & Fatty & $F A$ & $\begin{array}{l}\text { Fatty, mouth-coating residue on the palate, tongue, } \\
\text { and lips caused by fatty dairy products and emulsions } \\
\text { such as mayonnaise and salad dressings }\end{array}$ \\
\hline & Foamy & $F O$ & $\begin{array}{l}\text { Amount of force required to break the matrix of } \\
\text { babbles in a product }\end{array}$ \\
\hline & Cold & $\mathrm{CO}$ & Perceived temperature in the mouth \\
\hline
\end{tabular}

evaluated twice by each of the 11 panelists, and the resulting scores were used as the official data. The panelists cleansed their palates between samples with water, weak coarse green tea, and unsalted crackers.

\subsection{Measurement of fat destabilization rate}

The fat destabilization rate was measured using the method described by Kokubo et $a l{ }^{(9)}$ Specifically, ice cream samples collected before and after freezing were dissolved and dispersed under uniform conditions in a quantity of deionized water equal to three times their volume at 5 to $10^{\circ} \mathrm{C}$, and then gently agitated for a full day to remove air bubbles. The samples were then diluted to between 100 and 2,000 times and the size distributions of fat globules in each were measured using a laser diffraction particle size analyzer (LA-950V2; Horiba, Ltd., Japan).

The fat destabilization rate was determined based on the equation provided below. The resulting numerical value represents the percentage of fat globules in the prefrozen ice cream mix with a particle size of $\leq 90 \%\left(D_{90}\right.$ : particle size $(\mu \mathrm{m})$ that is 
$90 \%$ cumulative volume frequency in the prefrozen mix), which have agglomerated after freezing to have a particle size of $\geq 90 \%$. This value is taken as the rate of fat destabilization (FAT).

$$
\operatorname{FAT}(\%)=\frac{V_{\mathrm{Frez}}-10}{90} \times 100,
$$

$V_{\text {Frez: }}:$ cumulative volume frequency $(\%)$ of particles $\geq D_{90}$ in the postfrozen sample.

\subsection{Measurement of ice crystal diameter}

Observation of ice crystals was performed with a digital microscope (KH-7700; Hirox Co., Ltd., Japan) that was set up inside a temperature-controlled refrigerated glovebox. The internal temperature of the glovebox was set at $-15^{\circ} \mathrm{C}$. A small amount of ice cream was placed on a prechilled microscope slide and its fat content was removed by adding a few drops of isobutanol. Another prechilled slide was placed on the top of the sample and gently moved to disperse the ice crystals in the ice cream, thus ensuring that no overlapping occurred. The slide was then placed on the microscope stage and the ice crystals were observed.

The equivalent circle diameters (ECDs; $\mu \mathrm{m})$ were calculated from the images obtained, using image analysis software (Image-Pro Plus Version 4.0; Media Cybernetics, U.S.) based on the ice crystal area, and the mean was used as the ice crystal diameter (ICE).

\subsection{Measurement of air bubble diameter}

The ice cream was frozen in liquid nitrogen, after which fragments obtained by freeze-fracturing in the liquid nitrogen were inserted into the chamber of a scanning electron microscope (SEM; SM-200; Topcon Co., Ltd., Japan) fitted with a liquid nitrogen cold stage module (C1002; Gatan, U.K.). The fragments were etched by degassing/sublimation inside the SEM chamber, maintained at a temperature of $-95^{\circ} \mathrm{C}$, and their structures were then observed. The ECDs $(\mu \mathrm{m})$ were calculated from the images obtained, using image analysis software (Image-Pro Plus Version 4.0; Media Cybernetics, U.S.), based on the air bubble area, and the mean was used as the air bubble diameter (AIR).

\subsection{Odor sensor}

The odor sensor used in this study was an electronic nose system (FOX 3000; Alpha M.O.S., France) equipped with a sensor array consisting of 18 metal oxide semiconductor (MOS) sensors (LY2/LG, LY/G, LY2/AA, LY2/GH, LY2/gCHl, LY2/gCT, T30/1, P10/1, P10/2, P40/1, T70/2, PA/2, P30/1, P40/2, P30/2, T40/2, T40/1, and TA/2). These sensors measure the changes in electrical resistance that occur due to the adsorption and desorption of headspace volatile compounds. The sensitivity and selectivity of each sensor is dependent on the metals from which they are constructed. ${ }^{(19,20)}$ A $1 \mathrm{~g}$ sample of frozen ice cream was placed inside a special-purpose glass vial that was then sealed and heated at $37^{\circ} \mathrm{C}$ for five min. The vial headspace was then delivered to the sensors with pure air at a flow rate of $150 \mathrm{ml} / \mathrm{min}$ for $1 \mathrm{~s}$ and the change in electrical resistance was measured for 3,600 s, with this measurement performed a total of three times. The mean 
response score $(n=3)$ determined using eq. (3) below was used in the evaluation.

Odor sensor score $=($ Maximum resistance - Initial resistance $) /$ Initial resistance

\section{7 $\quad$ Model fitting}

Statistical analysis was performed using statistical software (JMP 8 statistical software; SAS Institute Inc., U.S.). Modeling was performed using a quadratic polynomial equation consisting of linear, quadratic, and interaction terms. Model parameters were predicted on the basis of least-squares multiple regression analysis. The significance of derived standard partial regression coefficients was evaluated with t-test, wherein terms with a p-value greater than 0.1 were deemed unnecessary and subsequently removed.

\section{Results and Discussion}

\subsection{Sensory evaluation}

The 12 sensory attributes obtained with QDA were used to evaluate 15 ice cream samples prepared under different process conditions. As a result, significant differences $(\alpha=0.05)$ were observed for 11 of these 12 sensory attributes, which were defined as overall vanilla intensity $(V I)$, creamy-vanillin $(C V)$, phenolic $(P H)$, caramel $(C A)$, fresh milk $(F M)$, skim milk $(S M)$, fatty dairy $(F D)$, fatty $(F A)$, foamy $(F O)$, and cold $(C O)$. See Table 5 for details. We assume that the individual process conditions and combination thereof caused changes in the ice cream sensory attributes. The fact that the remaining sensory parameter labeled creamy $(C R)$ did not exhibit any significant change $(\alpha=0.05)$ suggests that the process conditions examined in this study did not cause any change to this attribute. $F O$ in particular displayed the widest range between the maximum (82.1) and minimum (34.8) values, followed by $S M$ and $C O$ (62.5-20.0 and 72.7-30.5, respectively), which indicates that these sensory attributes were susceptible to substantial change, even under the manufacturing scope established in the present study.

\subsection{PCA of sensory attributes}

Of the 12 sensory attributes studied, the 11 found to be significant in ANOVA (i.e., all except $C R$ ) were subjected to principal component analysis (PCA) (Fig. 1(a)). The sum contribution of principal component 1 (PC1) and PC2 was $96.9 \%$, but PC1 alone comprised $92.8 \%$, and seems to be capable of fundamentally explaining the attribute variance. Furthermore, the factor loadings for each sensory attribute were characterized by their ability to be classified into two categories with the origin as the axis. We believe that this is because many of the sensory attributes obtained in this study shared a strong correlation. More specifically, there was a correlation between the aroma attributes of $V I, C V, P H, C A, F M$, and $F D$ along with the texture attribute of $C O$, and that the aroma attributes of $M I$ and $S M$ were similar to the textural attributes of $F A$ and $F O$. This finding suggests that the $\mathrm{PC} 1$ can be interrupted as the axis indicating the intensity of vanilla. Li et al. ${ }^{(6)}$ reported that components in vanilla extract other than vanillin are important for both the intensity and characteristics of vanilla flavor perception, suggesting that these 
Table 5

Sensory analysis of the ice creams by quantitative descriptive analysis.

\begin{tabular}{|c|c|c|c|c|c|c|c|c|c|c|c|c|}
\hline \multirow[b]{2}{*}{ Sample } & \multicolumn{12}{|c|}{ Attribute $^{1}$} \\
\hline & $V I^{*}$ & $C V^{*}$ & $P H^{*}$ & $C A^{*}$ & $M I^{*}$ & $F M^{*}$ & $S M^{*}$ & $F D^{*}$ & $C R$ & $F A^{*}$ & $F O^{*}$ & $\mathrm{CO}^{*}$ \\
\hline 1 & $39.1^{\text {bef }}$ & $33.4^{\text {efg }}$ & $11.4^{\mathrm{cd}}$ & $12.3^{\mathrm{cde}}$ & $61.4^{\mathrm{abc}}$ & $32.7^{\mathrm{cde}}$ & $49.6^{\mathrm{abc}}$ & $23.6^{c}$ & $34.1^{\mathrm{a}}$ & $63.2^{\mathrm{ab}}$ & $66.1^{\mathrm{b} .}$ & $37.3^{\mathrm{fg}}$ \\
\hline 2 & $43.2^{\mathrm{cde}}$ & $37.7^{\text {cdef }}$ & $11.4^{\mathrm{cd}}$ & $10.5^{\mathrm{cde}}$ & $58.6^{\text {bcd }}$ & $39.6^{\mathrm{bcd}}$ & $44.6^{\text {bcd }}$ & $30.0^{\mathrm{abc}}$ & $40.9^{\mathrm{a}}$ & $62.1^{\mathrm{abc}}$ & $63.2^{\mathrm{b}}$ & $42.3^{\text {ef }}$ \\
\hline 3 & $49.3^{\mathrm{bcd}}$ & $42.1^{\text {bcde }}$ & $18.6^{\text {bcd }}$ & $17.3^{\mathrm{abc}}$ & $49.8^{\text {cde }}$ & $45.9^{\mathrm{abc}}$ & $34.8^{\mathrm{cde}}$ & $29.6^{\mathrm{abc}}$ & $35.0^{\mathrm{a}}$ & $50.2^{\text {cde }}$ & $43.2^{\mathrm{c}}$ & $67.7^{\mathrm{ab}}$ \\
\hline 4 & $28.6^{\mathrm{f}}$ & $28.2^{\mathrm{fg}}$ & $9.1^{\mathrm{d}}$ & $4.6^{\mathrm{e}}$ & $70.0^{\mathrm{ab}}$ & $25.0^{\mathrm{e}}$ & $59.1^{\mathrm{ab}}$ & $30.9^{\mathrm{abc}}$ & $33.0^{\mathrm{a}}$ & $68.6^{\mathrm{ab}}$ & $82.1^{\mathrm{a}}$ & $30.5^{\mathrm{g}}$ \\
\hline 5 & $41.8^{\text {cdef }}$ & $38.0^{\text {cdef }}$ & $9.6^{\mathrm{d}}$ & $7.7^{\mathrm{de}}$ & $59.1^{\mathrm{abcd}}$ & $35.5^{\text {cde }}$ & $48.9^{\mathrm{abc}}$ & $25.0^{\mathrm{bc}}$ & $36.4^{\mathrm{a}}$ & $59.6^{\text {bcd }}$ & $63.2^{\mathrm{b}}$ & $49.1^{\mathrm{de}}$ \\
\hline 6 & $54.1^{\mathrm{abc}}$ & $45.2^{\mathrm{abcd}}$ & $21.8^{\mathrm{abc}}$ & $20.5^{\mathrm{ab}}$ & $47.7^{\mathrm{def}}$ & $51.8^{\mathrm{ab}}$ & $31.1^{\mathrm{de}}$ & $30.5^{\mathrm{abc}}$ & $40.0^{\mathrm{a}}$ & $47.7^{\mathrm{de}}$ & $42.7^{c}$ & $67.7^{\mathrm{ab}}$ \\
\hline 7 & $31.8^{\mathrm{ef}}$ & $29.1^{\mathrm{fg}}$ & $7.3^{\mathrm{d}}$ & $7.3^{\mathrm{de}}$ & $66.8^{\mathrm{ab}}$ & $28.6^{\text {de }}$ & $57.3^{\mathrm{ab}}$ & $24.6^{\mathrm{bc}}$ & $32.7^{\mathrm{a}}$ & $66.8^{\mathrm{ab}}$ & $79.1^{\mathrm{a}}$ & $35.3^{\mathrm{fg}}$ \\
\hline 8 & $32.7^{\mathrm{ef}}$ & $31.4^{\mathrm{fg}}$ & $9.1^{\mathrm{d}}$ & $5.5^{\mathrm{e}}$ & $65.0^{\mathrm{ab}}$ & $31.4^{\mathrm{de}}$ & $55.9^{\mathrm{ab}}$ & $27.7^{\mathrm{abc}}$ & $31.8^{\mathrm{a}}$ & $69.3^{\mathrm{ab}}$ & $74.6^{\mathrm{ab}}$ & $35.5^{\mathrm{fg}}$ \\
\hline 9 & $60.9^{\mathrm{ab}}$ & $49.1^{\mathrm{ab}}$ & $30.0^{\mathrm{ab}}$ & $23.6^{\mathrm{a}}$ & $40.9^{\mathrm{ef}}$ & $51.8^{\mathrm{ab}}$ & $30.2^{\mathrm{de}}$ & $35.5^{\mathrm{ab}}$ & $33.2^{\mathrm{a}}$ & $49.1^{\mathrm{de}}$ & $40.9^{c}$ & $58.9^{\mathrm{bcd}}$ \\
\hline 10 & $62.3^{\mathrm{ab}}$ & $47.3^{\mathrm{abc}}$ & $31.4^{\mathrm{a}}$ & $23.9^{a}$ & $39.1^{\mathrm{ef}}$ & $53.4^{\mathrm{a}}$ & $25.0^{\mathrm{e}}$ & $35.5^{\mathrm{ab}}$ & $36.8^{a}$ & $42.7^{\mathrm{e}}$ & $34.8^{c}$ & $72.7^{\mathrm{a}}$ \\
\hline 11 & $35.5^{\text {ef }}$ & $36.4^{\text {defg }}$ & $10.9^{\mathrm{cd}}$ & $9.6^{\text {de }}$ & $65.0^{\mathrm{ab}}$ & $29.6^{\text {de }}$ & $54.3^{\mathrm{ab}}$ & $28.2^{\mathrm{abc}}$ & $36.1^{\mathrm{a}}$ & $65.9^{\mathrm{ab}}$ & $71.8^{\mathrm{ab}}$ & $38.6^{\text {efg }}$ \\
\hline 12 & $61.8^{\mathrm{ab}}$ & $49.1^{\mathrm{ab}}$ & $26.8^{\mathrm{ab}}$ & $25.0^{\mathrm{a}}$ & $39.1^{\mathrm{ef}}$ & $51.8^{\mathrm{ab}}$ & $25.0^{\mathrm{e}}$ & $31.4^{\mathrm{abc}}$ & $36.4^{\mathrm{a}}$ & $48.6^{\text {de }}$ & $43.2^{\mathrm{c}}$ & $55.0^{\mathrm{cd}}$ \\
\hline 13 & $39.1^{\text {bef }}$ & $34.6^{\mathrm{efg}}$ & $10.9^{\mathrm{cd}}$ & $11.8^{\text {cde }}$ & $60.9^{\mathrm{abcd}}$ & $34.3^{\text {cde }}$ & $49.3^{\mathrm{abc}}$ & $28.0^{\mathrm{abc}}$ & $34.6^{\mathrm{a}}$ & $63.2^{\mathrm{ab}}$ & $65.0^{\mathrm{b}}$ & $42.3^{\text {ef }}$ \\
\hline 14 & $28.6^{\mathrm{f}}$ & $26.4^{\mathrm{g}}$ & $7.3^{\mathrm{d}}$ & $3.6^{\mathrm{e}}$ & $72.3^{\mathrm{a}}$ & $24.6^{\mathrm{e}}$ & $62.5^{\mathrm{a}}$ & $26.4^{\mathrm{abc}}$ & $30.0^{\mathrm{a}}$ & $71.8^{\mathrm{a}}$ & $81.1^{\mathrm{a}}$ & $31.8^{\mathrm{fg}}$ \\
\hline 15 & $66.6^{\mathrm{a}}$ & $55.0^{\mathrm{a}}$ & $26.8^{\mathrm{ab}}$ & $27.3^{\mathrm{a}}$ & $35.9^{f}$ & $55.5^{\mathrm{a}}$ & $20.0^{\mathrm{e}}$ & $37.3^{\mathrm{a}}$ & $39.1^{\mathrm{a}}$ & $46.4^{\mathrm{e}}$ & $40.0^{c}$ & $60.9^{\mathrm{bc}}$ \\
\hline
\end{tabular}

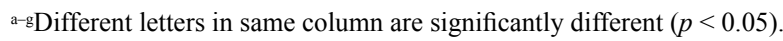

Sensory score range are 0 (none)-100 (extreme).

${ }^{1} V I=$ overall vanilla intensity; $C V=$ creamy-vanillin; $P H=$ phenolic; $C A=$ caramel; $M I=$ overall milk intensity; $F M=$ fresh milk; $S M=$ skim milk powder; $F D=$ fatty-dairy; $C R=$ creamy; $F A=$ fatty; $F O=$ foamy; $C O=$ cold.

other components are also essential to enhance vanilla flavor perception. The present study's finding of a strong correlation between $V I$ and other sensory parameters, in addition to the vanillin aroma-defining attribute of $C V$, does not contradict this assertion.

Cluster analysis (by Ward's method) of the sensory evaluation scores for samples, in terms of the PC1 and PC2 PCA scores for the sensory evaluations of each sample, yielded the following three cluster groups: Group 1 that had a positive correlation with PC1 $(3,6,9,10,12,15)$; Group 2 that had a low correlation $(1,2,5,13)$; and Group 3 that had a negative correlation $(4,7,8,11,14)$. The fact that samples 1,2 , and 13 , which are central to the experiment, belonged to Group 2 (located close to the origin) also lends credence to the theory that the process conditions altered sensory perceptions of the ice cream samples.

\subsection{PCA of odor sensor scores}

Sensory evaluation is a time-consuming and costly process, so the use of sensors to expedite the acquisition of results has many advantages in terms of food quality control. With this in mind, we used an odor sensor on the 15 samples prepared under different process conditions to assess whether such a sensor could detect the sensory evaluations obtained by QDA. ANOVA of measurement results revealed them to be statistically 


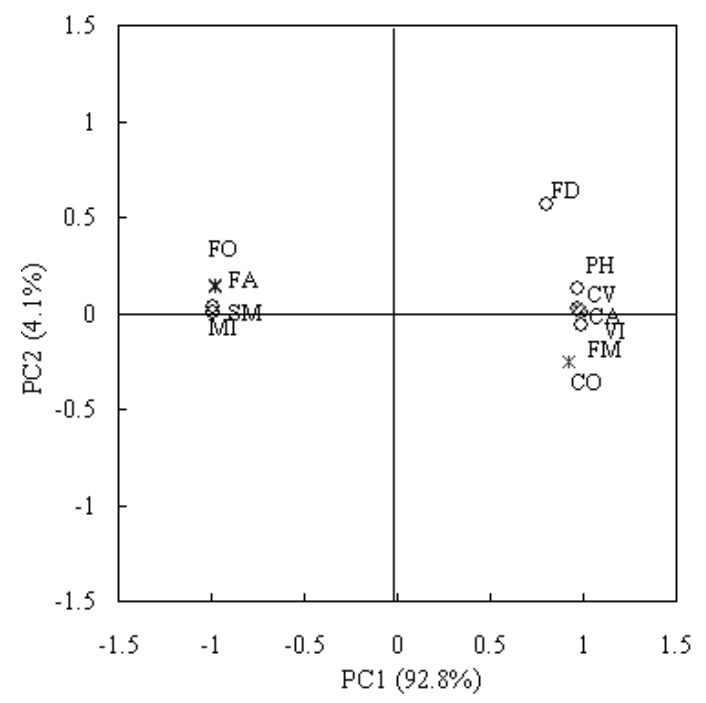

(a)

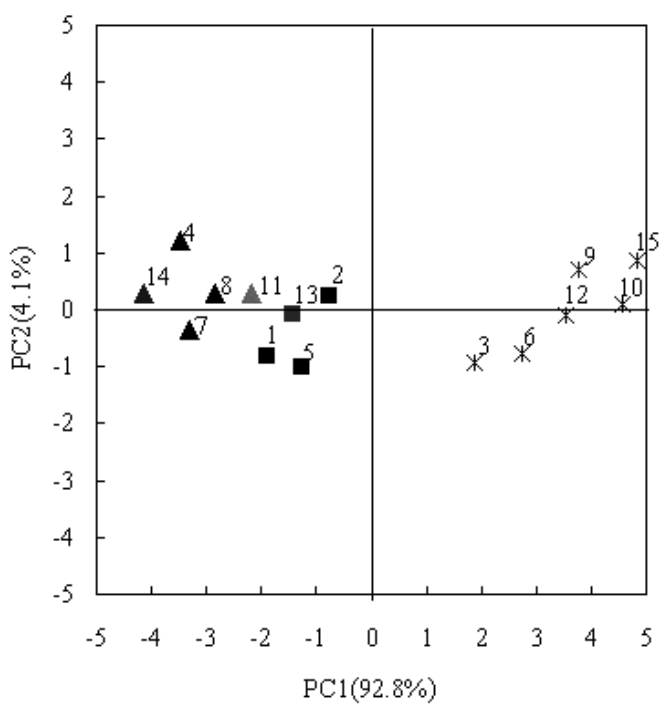

(b)

Fig. 1. PCA applied to the sensory scores ((a) loading plot, (b) PCA score). *: Group 1 (3, 6, 9, 10, 12, 15), $\mathbf{m}$ : Group $2(1,2,5,13), \boldsymbol{\Delta}$ Group $3(4,7,8,11,14)$ categorized by cluster analysis (Ward method).

significant $(\alpha=0.05)$ for nine of the 18 sensors, namely, LY2/G, LY2/AA, LY/GH, LY/ $\mathrm{gCT} 1, \mathrm{~T} 70 / 2, \mathrm{PA} / 2, \mathrm{P} 30 / 1, \mathrm{P} 40 / 2$, and P30/2.

These nine sensor response values were then subjected to PCA (Fig. 2). The contribution of $\mathrm{PC} 1$ was $97.1 \%$, so the variation can largely be explained in terms of PC1. The sensors could be classified into two groups: those having a negative correlation with $\mathrm{PC} 1$ (LY2/G, LY2/AA, LY2/GH, LY2/gCTl) and those having a positive correlation with PC1 (T70/2, PA/2, P30/1, P40/2, P30/2) (Fig. 2(a)). However, examination of PCA scores (Fig. 2(b)) for each sample suggested the possibility that the detection accuracy may have been low because the distribution of scores for samples 1, 2, and 13, which shared the same process conditions, was inconsistent compared with the sensory evaluation PCA results (Fig. 1(b)).

\subsection{Relationship between sensory attributes and process conditions}

We determined the correlation coefficients between the 11 sensory attributes (all except $C R$ ) and the process conditions for each sample to investigate the relationship between the sensory evaluation results and the process conditions (Table 6). There were reasonably strong correlations shown between nine of these 11 attributes (all except $C O$ and $F D$ ) and $O v r$. Accordingly, we consider it plausible that overrun has a broad- 


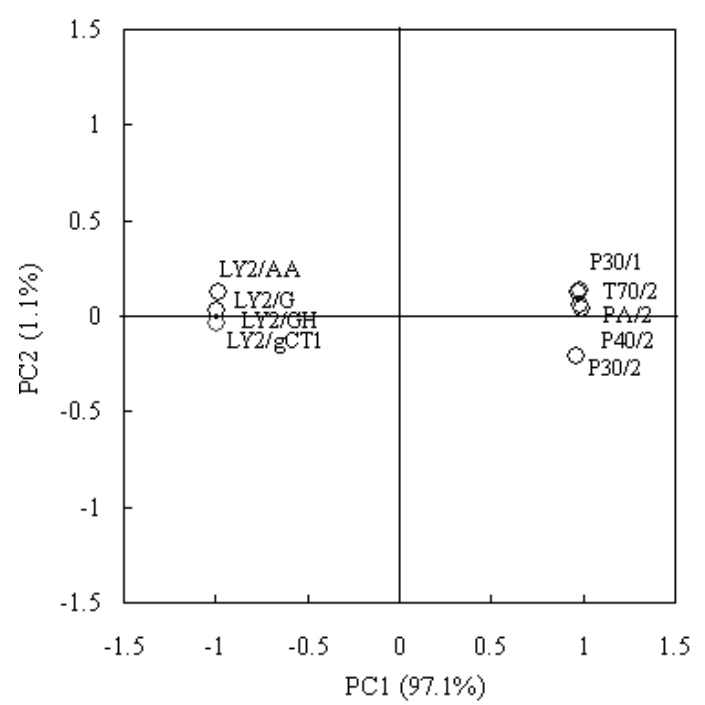

(a)

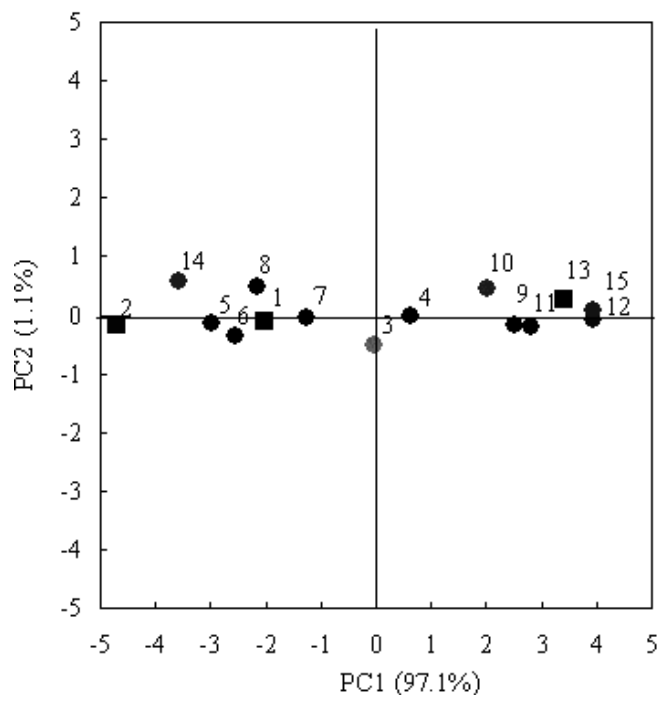

(b)

Fig. 2. Principal component analysis applied to the odor sensor scores ((a) loading plot, (b) PCA score).

Table 6

Correlation coefficients between process parameters and sensory attributes.

\begin{tabular}{lrrr}
\hline Sensory & \multicolumn{1}{c}{ Pre } & \multicolumn{1}{c}{ Tem } & \multicolumn{1}{c}{ Ovr } \\
\hline$V I$ & 0.02 & 0.36 & -0.86 \\
$C V$ & -0.03 & 0.32 & -0.83 \\
$P H$ & -0.06 & 0.29 & -0.86 \\
$C A$ & 0.03 & 0.27 & -0.91 \\
$M I$ & 0.02 & -0.35 & 0.86 \\
$F M$ & 0.02 & 0.44 & -0.81 \\
$S M$ & -0.03 & -0.37 & 0.84 \\
$F D$ & -0.05 & 0.13 & -0.68 \\
$F A$ & -0.02 & -0.48 & 0.80 \\
$F O$ & 0.07 & -0.52 & 0.80 \\
$C O$ & -0.03 & 0.65 & -0.66 \\
\hline
\end{tabular}

Creamy $(C R)$ was deleted $(p>0.05$ in ANOVA test).

spectrum effect on sensory perceptions. There was a particularly strong correlation with $C A(R=-0.91)$, which suggested that an intense caramel sensation occurs when ice cream overrun is low. There was also a relatively strong correlation between Tem and 
the textural attributes of $F A, F O$, and $C O$, from which we can infer that changing Tem affects texture rather than aroma attributes. The correlation coefficient between Tem and $C O$ was 0.65 , and ice cream with a high drawing temperature tended to produce a cold sensation in the mouth. On the other hand, Pre did not exhibit a correlation with any of the sensory attributes. Iwatsuki et al. ${ }^{(21)}$ reported that because the homogenization pressure in dairy manufacturing processes reduces the size of fat globules, lower homogenization pressures increase milk's fattiness sensation and richness and improve palatability. Meanwhile, Mizota et al. ${ }^{(18)}$ report that taste sensor analysis can be used to distinguish milk produced with different homogenization pressures. Homogenization pressure brings about a change in the sensory perception of foods that are consumed in an emulsified state such as milk. However, in the case of ice cream, where the emulsion is broken during the freezing process, it was assumed that the impact of fat particle size on sensory perception had diminished.

These findings suggest that the sensory attributes of ice cream are significantly influenced by freezer $O v r$. Additionally, Tem had a comparatively strong correlation with texture attributes compared with the other sensory attributes. Specifically, when $O v r$ was low, the sensory attributes of $V I, C V, P H, C A, F M, F D$, and $C O$ became more intense. In contrast, when $O v r$ was high, there was an increase in intensity of $M I, S M, F A$, and $F O$. Furthermore, lowering the drawing temperature tended to increase $F A$ and $F O$ but reduce CO.

We performed process condition modeling using $V I$ as a typical sensory indicator to better clarify the quantitative relationship between the manufacturing process and sensory perception. The derived model equation is as follows:

$$
\text { Overall vanilla intensity }(V I)=41.72+6.22 \mathrm{Tem}-14.97 \mathrm{Ovr}+6.21 O v r^{2}
$$

The model proved to be effective based on a significant ANOVA result $(p<0.0001)$, a high coefficient of determination at $R^{2}=0.922$ (adjusted $R^{2}=0.901$ ), and insignificant model LOF (lack of fit; $p=0.105$ ). The response surface plot of our model (Fig. 3) makes it clear that when the drawing temperature is high and overrun is low, there is an increase in vanilla flavor perception.

\subsection{Relationship between process conditions and microstructural attributes}

Ice cream is a complex food colloid, the microstructure of which consists of air bubbles, fat globules, ice crystals, and an unfrozen serum phase. ${ }^{(22)}$ The rate of fat destabilization and the diameter of ice crystals and air bubbles for the 15 ice cream samples in the present study are shown in Table 7 . Within the range of process conditions of this study, the mean ice crystal size was $28.57-76.89 \mu \mathrm{m}$ and the mean air bubble size was $23.46-91.97 \mu \mathrm{m}$. According to a study by Cook and Hartel, ${ }^{(23)}$ ice crystals in ice cream range in size from approximately 1 to over $150 \mu \mathrm{m}$ in diameter with an average size of approximately $35 \mu \mathrm{m}$, while air bubbles typically range from approximately 20 to $50 \mu \mathrm{m}$ in diameter. With this in mind, the process conditions of the present study are deemed sufficient in scope to determine the correlation between ice cream's microstructure and sensory perception.

Table 8 shows the correlation coefficients between process conditions and the 


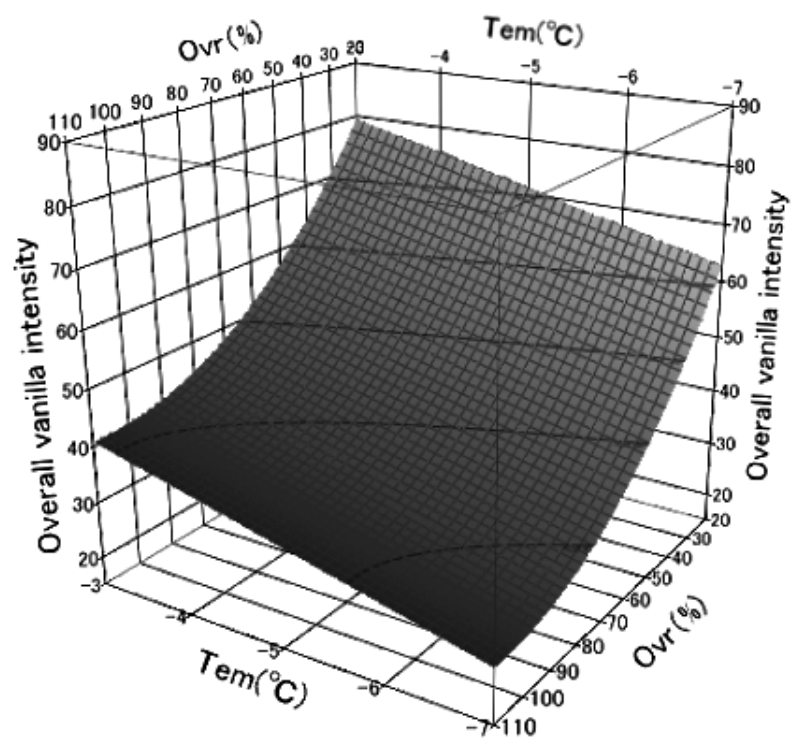

Fig. 3. Response surface plot for overall vanilla intensity. Tem: drawing temperature $\left({ }^{\circ} \mathrm{C}\right)$, Ovr: overrun (\%).

Table 7

Microstructural attributes of each ice cream sample.

\begin{tabular}{lrcc}
\hline & \multicolumn{3}{c}{ Microstructure } \\
\cline { 2 - 4 } Sample & $F A T(\%)$ & $I C E(\mu \mathrm{m})$ & $A I R(\mu \mathrm{m})$ \\
\hline 1 & 61.98 & 40.63 & 41.97 \\
2 & 47.18 & 45.61 & 43.52 \\
3 & 3.21 & 76.89 & 67.29 \\
4 & 92.19 & 28.57 & 27.81 \\
5 & 50.71 & 42.28 & 91.97 \\
6 & 71.59 & 69.47 & 56.74 \\
7 & 97.49 & 35.11 & 23.46 \\
8 & 55.73 & 41.28 & 42.09 \\
9 & 62.43 & 54.43 & 38.36 \\
10 & 12.85 & 73.47 & 68.09 \\
11 & 86.71 & 38.39 & 24.48 \\
12 & 86.81 & 38.15 & 26.59 \\
13 & 70.81 & 49.01 & 45.91 \\
14 & 81.84 & 45.91 & 43.70 \\
15 & 61.01 & 59.25 & 34.23 \\
\hline
\end{tabular}


microstructural attributes of ice cream. No correlation could be confirmed between the microstructural attributes and homogenization pressure (Pre), but a high correlation was demonstrated for freezing conditions. Ice cream freezing temperature $(T e m)$, in particular, exhibited a strong correlation with all three microstructural attributes $(R=$ $-0.79 / 0.79 / 0.90$ for $F A T / I C E / A I R$, respectively), suggesting that drawing temperature is the primary factor that determines ice cream microstructure. In other words, if the drawing temperature is low during freezing, the fat globules are more destabilized and the ice crystals and air bubbles become minute. This finding validates our previous study in $2008,{ }^{(11)}$ which demonstrated that drawing temperature is, more than any of the other conditions related to freezing, the key determinant of ice cream structure.

\subsection{Relationship between ice cream microstructure and sensory attributes}

We determined the correlations between the sensory attributes and FAT, ICE, and $A I R$ for each ice cream sample (Table 9). A distinguishing feature of these results is the presence of a strong correlation between the ice crystal diameter ICE and the textural sensory attributes $F A, F O$, and $C O$, which implies that ice crystal size plays an important role in the mouthfeel of ice cream. The high correlation with $C O$, in particular $(R=0.87)$, supports the theory that the coldness of ice cream increases when the ice crystals are larger. The correlation between ice size and aroma attribute $F M$ was also high, so we are of the opinion that large ice crystals bestow sensory attributes more akin to those of fresh

Table 8

Correlation coefficients between process parameters and microstructural attributes of ice cream.

\begin{tabular}{lrrr}
\hline Process & FAT & ICE & \multicolumn{1}{c}{ AIR } \\
\hline Pre & 0.36 & -0.01 & -0.07 \\
Tem & -0.79 & 0.79 & 0.90 \\
Ovr & 0.20 & -0.44 & 0.19 \\
\hline
\end{tabular}

Table 9

Correlation coefficients between microstructural attributes and sensory attributes.

\begin{tabular}{lrrr}
\hline Sensory & $F A T$ & $I C E$ & AIR \\
\hline$V I$ & -0.41 & 0.63 & 0.18 \\
$C V$ & -0.38 & 0.60 & 0.16 \\
$P H$ & -0.38 & 0.63 & 0.10 \\
$C A$ & -0.33 & 0.62 & 0.05 \\
$M I$ & 0.43 & -0.63 & -0.18 \\
$F M$ & -0.46 & 0.71 & 0.23 \\
$S M$ & 0.44 & -0.67 & -0.18 \\
$F D$ & -0.28 & 0.50 & -0.08 \\
$F A$ & 0.51 & -0.75 & -0.31 \\
$F O$ & 0.56 & -0.77 & -0.33 \\
$C O$ & -0.64 & 0.87 & 0.47 \\
\hline
\end{tabular}


milk. Adversely, there was a negative correlation between $F A T$ and the sensory attribute $C O(R=-0.64)$. When the fat destabilizes, there is a tendency to inhibit ice cream's $C O$.

No correlations with the sensory attributes were observed for AIR (which indicates the size of air bubbles) but strong correlations were seen for $O v r$ (Table 6). In continuous freezer systems, $O v r$ is a configurable control parameter, the value of which indicates the amount of air in the ice cream. Therefore, we consider it likely that the amount of air is more important in determining sensory perception of ice cream than air bubble size.

The above suggests that, on one hand, the process condition $O v r$ is the one that is most involved in the determination of the sensory attributes across the board (via the amount of air in the ice cream's microstructure), while on the other hand, the drawing temperature Tem, which exhibits a strong correlation with the microstructural attributes, appears to affect changes in textural attributes $(F A, F O$, and $C O)$ via the microstructural attributes it changes, namely, the size of the ice crystals (and fat destabilization rate).

\subsection{Relationship between odor sensor scores and process conditions, microstructure, and sensory attributes}

The findings of the present study revealed that process conditions lead to changes in the structural conditions of the ice cream, which consequently alter the sensory attributes. We therefore investigated whether the sensory attributes of aroma and texture resulting from differences in the ice cream's microstructure were detectable using an odor sensor. The correlation between the attributes and the nine sensors yielding significant ANOVA results (LY2/G, LY2/AA, LY/GH, LY/gCT1, T70/2, PA/2, P30/1, P40/2, P30/2) were all very high $(R>0.95)$. Accordingly, we studied the correlation coefficients with each of the ice cream attributes using the PA/2 MOS sensor as a representative sensor.

In terms of the process conditions, the representative sensor PA/2 was somewhat correlated with the $O v r$ parameter $(R=-0.62)$, indicating the ratio of air in the ice cream (Table 10). This may have been due to the release of volatiles trapped in air cells inside the ice cream upon melting. The aroma-related sensory attributes of $M I$ and $S M$ were high for ice cream samples with high overrun, so we suspect that the volatiles corresponding to these attributes that were trapped in air cells inside the ice cream were released due to melting. However, absolutely no correlation was seen between PA/2 sensor scores and the microstructural attributes FAT, ICE, and AIR. King ${ }^{(24)}$ reported that fat conditions in vanilla ice cream affect the flavor release pattern. Judging from the present study's similar finding that ice crystal size and fat destabilization rate affected sensory attributes, it was considered likely that it would be difficult to detect these differences using an odor sensor.

Despite the low correlation between the PA/2 sensor scores and sensory attributes, the relationships were remarkable in that they could be classified into two groups: one with positive correlations for attributes belonging to the same group ( $V I, C V$, $P H, C A, F M, F D, C O)$ and one with negative correlations $(M I, S M, F A, F O)$. Future studies incorporating aroma and other analyses may help to shed more light on these relationships. 
Table 10

Correlation coefficient between PA/2 sensor scores and ice cream attributes.

\begin{tabular}{lcr}
\hline Category & Attribute & \multicolumn{1}{c}{$R$} \\
\hline Process & Pre & -0.22 \\
& Tem & -0.34 \\
Microstructure & Ovr & -0.62 \\
& $F A T$ & 0.11 \\
& $I C E$ & 0.04 \\
Sensory & AIR & -0.36 \\
& $V I$ & 0.48 \\
& $C V$ & 0.52 \\
& $P H$ & 0.55 \\
& $C A$ & 0.56 \\
& $M I$ & -0.50 \\
& $F M$ & 0.39 \\
& $S M$ & -0.47 \\
& $F D$ & 0.58 \\
& $F A$ & -0.41 \\
& $F O$ & -0.40 \\
& $C O$ & 0.28 \\
\hline
\end{tabular}

\section{Conclusions}

We investigated the effects of freezing process (which substantially influence microstructural and physical properties), and homogenization process (which determines fat particle size), on the sensory attributes of ice cream. The sensory evaluation findings revealed significant differences between the ice cream samples prepared under different process conditions for 11 of the 12 sensory attributes used in our evaluation. This indicates that, even when the ingredients were the same, differences in the microstructure of the ice cream governed by the process conditions used resulted in sensory perception changes. For instance, low Ovr and high Tem freezer settings enhanced the VI of the ice cream because microstructural ice crystals increased in size, while fat destabilization and air volume were inhibited.

We also observed a correlation between the odor sensor response and the $O v r$ process condition, which suggested that the presence of air in ice cream affects aroma components. However, the odor sensor was incapable of a distinct classification of the sensory attributes revealed by sensory evaluation. Texture is emphasized in semisolid foods such as ice cream, so it is conceivable that the structural and physiochemical changes to ice cream that occur inside the mouth also affect the sensory attributes, and that this in turn makes it difficult to evaluate ice cream's flavor with an odor sensor. In light of these challenges, future studies into assessment systems will be required when introducing new sensor technologies for use in ice cream flavor evaluations. 


\section{References}

1 A. M. Roland, L. G. Phillips and K. J. Boor: J. Dairy Sci. 82 (1999) 32.

2 A. M. Roland, L. G. Phillips and K. J. Boor: J. Dairy Sci. 82 (1999) 2094.

3 R. L. Ohmes, R. T. Marshall and H. Heymann: J. Dairy Sci. 81 (1998) 1222.

4 J. X. Guinard, C. Zoumas-Morse, L. Mori, B. Uatoni, D. Panyam and A. Kilara: J. Food Sci. 62 (1997) 1087.

5 L. Hyvönen, M. Linna, H. Tuorila and G. Dijksterhuis: J. Dairy Sci. 86 (2003) 1130.

6 Z. Li, R. Marshall, H. Heymann and L. Fernando: J. Dairy Sci. 80 (1997) 3133.

7 J. P. Schirle-Keller, G. A. Reineccius and L. C. Hatchwell: J. Food Sci. 59 (1994) 813, 875.

8 A. S. Akalin, C. Karagözlü, G. Ender and G. Ünal: Milchwissenschaft 63 (2008) 293.

9 S. Kokubo, K. Sakurai, K. Hakamata, M. Tomita and S. Yoshida: Milchwissenschaft 51 (1996) 262.

10 E. J. Windhab and H. Wildmoser: Bull. IDF 374 (2002) 43.

11 K. Inoue, H. Ochi, M. Taketsuka, H. Saito, K. Sakurai, N. Ichihashi, K. Iwatsuki and S. Kokubo: J. Dairy Sci. 91 (2008) 1722.

12 K. Inoue, H. Ochi, K. Habara, M. Taketsuka, H. Saito, N. Ichihashi and K. Iwatsuki: J. Dairy Sci. 92 (2009) 5834.

13 K. Inoue, H. Ochi, M. Takestuka, H. Saito, N. Ichihashi, K. Iwatsuki and K. Toko: Jpn. J. Taste Smell Res. 17 (2010) 355.

14 C. Druaux and A. Voilley: Trends Food Sci. Technol. 8 (1997) 364.

15 T. Aishima: J. Agric. Food Chem. 39 (1991) 752.

16 K. Murakami, M. Akiyama, M. Sumi, M. Ikeda, K. Iwatsuki, O. Nishimura and K. Kumazawa: Food Sci. Technol. Res. 16 (2010) 99.

17 T. Michishita, M. Akiyama, Y. Hirano, M. Ikeda, Y. Sagara and T. Araki: J. Food Sci. 75 (2010) S477.

18 Y. Mizota, H. Matsui, M. Ikeda, N. Ichihashi, K. Iwatsuki and K. Toko: Sens. Mater. 20 (2008) 243.

19 Odor Sensor Technical Note Number 1 (Alpha M.O.S., Toulouse, France, 1998).

20 Fox2000/3000/4000 Electronic Nose Advance User Manual (Alpha M.O.S., Toulouse, France, 2000).

21 K. Iwatsuki, H. Matsui, Y. Mizota, K. Sotoyama, M. Sumi and M. Tomita: J. Jpn. Soc. Food Sci. Technol. 48 (2001) 126.

22 H. D. Goff: Int. Dairy J. 7 (1997) 363.

23 K. L. K. Cook and R. W. Hartel: CRFSFS 9 (2010) 213.

24 B. M. King: Lebensm. Wiss. Technol. 27 (1994) 450. 